The Journal of Nonlinear $\mathbf{S}_{\text {cience and Aplications }}$ http://www.tjnsa.com

\title{
A GENERALIZATION OF NADLER'S FIXED POINT THEOREM
}

\author{
M. ESHAGHI GORDJI*, H. BAGHANI, H. KHODAEI AND M. RAMEZANI
}

Abstract. In this paper, we prove a generalization of Nadler's fixed point theorem [S.B. Nadler Jr., Multi-valued contraction mappings, Pacific J. Math. 30 (1969) 475-487].

\section{INTRODUCTION AND PRELIMINARIES}

Let $(X, d)$ be a metric space. $C B(X)$ denotes the collection of all nonempty closed bounded subsets of $X$. For $A, B \in C B(X)$, and $x \in X$, define $D(x, A):=$ $\inf \{d(x, a) ; a \in A\}$, and

$$
H(A, B):=\max \left\{\sup _{a \in A} D(a, B), \sup _{b \in B} D(b, A) .\right.
$$

It is easy to see that $H$ is a metric on $C B(X) . H$ is called the Hausdorff metric induced by $d$.

Definition 1.1. An element $x \in X$ is said to be a fixed point of a multi-valued mapping $T: X \rightarrow C B(X)$, if such that $x \in T(x)$.

One can show that $(C B(X), H)$ is a complete metric space, whenever $(X, d)$ is a complete metric space (see for example Lemma 8.1.4, of [6]).

In 1969, Nadler [3] extended the Banach contraction principle [1] to set-valued mappings. In this paper among other things, we give a generalization of Nadler's fixed point theorem. The following lemma has important role in the proof of main theorem.

Date: Received: 24 Jan. 2010.

* Corresponding author.

2000 Mathematics Subject Classification. 54H25.

Key words and phrases. Hausdorff metric; Set-valued contraction; Nadler's fixed point theorem. 
Lemma 1.2. (3) Let $(X, d)$ be a metric space and $A, B \in C B(X)$. Then for each $a \in A$ and $\epsilon>0$ there exists an $b \in B$ such that

$$
d(a, b) \leq H(A, B)+\epsilon .
$$

\section{MAin Results}

We start our work with our main result, which can be regarded as an extension of Nadler's fixed point theorem.

Theorem 2.1. Let $(X, d)$ be a complete metric space and let $T$ be a mapping from $X$ into $C B(X)$ such that

$$
H(T x, T y) \leq \alpha d(x, y)+\beta[D(x, T x)+D(y, T y)]+\gamma[D(x, T y)+D(y, T x)]
$$

for all $x, y \in X$, where $\alpha, \beta, \gamma \geq 0$ and $\alpha+2 \beta+2 \gamma<1$. Then $T$ has a fixed point.

Proof. Let $x_{0} \in X, x_{1} \in T x_{0}$ and define $r:=\frac{\alpha+\beta+\gamma}{1-(\beta+\gamma)}$. If $r=0$ then proof is clear. Now, assume $r>0$, then it follows from Lemma 1.2 that

$$
\left\{\begin{array}{lr}
\exists x_{2} \in T x_{1} ; & d\left(x_{1}, x_{2}\right) \leq H\left(T x_{0}, T x_{1}\right)+r, \\
\exists x_{3} \in T x_{2} ; & d\left(x_{2}, x_{3}\right) \leq H\left(T x_{1}, T x_{2}\right)+r^{2}, \\
\cdot & \\
\cdot & d\left(x_{n}, x_{n+1}\right) \leq H\left(T x_{n-1}, T x_{n}\right)+r^{n} .
\end{array}\right.
$$

Hence, we have

$$
\begin{aligned}
d\left(x_{n}, x_{n+1}\right) \leq & H\left(T x_{n-1}, T x_{n}\right)+r^{n} \\
\leq & \alpha d\left(x_{n-1}, x_{n}\right)+\beta\left[D\left(x_{n}, T x_{n}\right)+D\left(x_{n-1}, T x_{n-1}\right)\right] \\
& \left.+\gamma\left[D\left(x_{n}, T x_{n-1}\right)+D\left(x_{n-1}, T x_{n}\right)\right)\right]+r^{n} \\
\leq & \alpha d\left(x_{n-1}, x_{n}\right)+\beta\left[d\left(x_{n}, x_{n+1}\right)+d\left(x_{n-1}, x_{n}\right)\right] \\
& +\gamma\left[d\left(x_{n-1}, x_{n}\right)+d\left(x_{n}, x_{n+1}\right)\right]+r^{n}
\end{aligned}
$$

for all $n \in \mathbf{N}$. It follows that

$$
d\left(x_{n}, x_{n+1}\right) \leq r d\left(x_{n-1}, x_{n}\right)+\frac{r^{n}}{1-(\beta+\gamma)}
$$

for all $n \in \mathbf{N}$. It can be conclude that

$$
d\left(x_{n}, x_{n+1}\right) \leq r^{n} d\left(x_{0}, x_{1}\right)+\frac{n r^{n}}{1-(\beta+\gamma)}
$$

for all $n \in \mathbf{N}$. Now, since $r<1$, then $\sum_{n=1}^{\infty} d\left(x_{n}, x_{n+1}\right)<\infty$. It follows that $\left\{x_{n}\right\}$ is a Cauchy sequence in $X$. By completeness of $X$, there exists $x^{*} \in X$ such 
that $\lim _{n \rightarrow \infty} x_{n}=x^{*}$. We are going to show that $x^{*}$ is a fixed point of $T$. We have

$$
\begin{aligned}
D\left(x^{*}, T x^{*}\right) \leq & d\left(x^{*}, x_{n+1}\right)+D\left(x_{n+1}, T x^{*}\right) \leq d\left(x^{*}, x_{n+1}\right)+H\left(T x_{n}, T x^{*}\right) \\
\leq & d\left(x^{*}, x_{n+1}\right)+\alpha d\left(x_{n}, x^{*}\right)+\beta\left[D\left(x_{n}, T x_{n}\right)+D\left(x^{*}, T x^{*}\right)\right] \\
& +\gamma\left[D\left(x_{n}, T x^{*}\right)+D\left(x^{*}, T x_{n}\right)\right]
\end{aligned}
$$

for all $n \in \mathbf{N}$. Therefore,

$$
\begin{aligned}
D\left(x^{*}, T x^{*}\right) \leq & d\left(x^{*}, x_{n+1}\right)+\alpha d\left(x_{n}, x^{*}\right)+\beta\left[d\left(x_{n}, x_{n+1}\right)+D\left(x^{*}, T x^{*}\right)\right] \\
& +\gamma\left[D\left(x_{n}, T x^{*}\right)+d\left(x_{n+1}, x^{*}\right)\right]
\end{aligned}
$$

for all $n \in \mathbf{N}$. Passing the limit $n \rightarrow \infty$ in (1), then we have

$$
D\left(x^{*}, T x^{*}\right) \leq(\beta+\gamma) D\left(x^{*}, T x^{*}\right) .
$$

On the other hand $\beta+\gamma<1$, then $D\left(x^{*}, T x^{*}\right)=0$. It follows that $x^{*} \in T x^{*}$.

Corollary 2.2. ([2]; page 201) Let $(X, d)$ be a complete metric space and let $T$ be a mapping from $X$ into $X$ such that

$$
d(T x, T y) \leq \alpha d(x, y)+\beta[d(x, T x)+d(y, T y)]+\gamma[d(x, T y)+d(y, T x)]
$$

for all $x, y \in X$, where $\alpha, \beta, \gamma \geq 0$ and $\alpha+2 \beta+2 \gamma<1$. Then $T$ has a fixed point.

Corollary 2.3. Let $(X, d)$ be a complete metric space and let $T$ be a mapping from $(X, d)$ into $(C B(X), H)$ satisfies

$$
H(T x, T y) \leq a_{1} d(x, y)+a_{2} D(x, T x)+a_{3} D(y, T y)+a_{4} D(x, T y)+a_{5} D(y, T x)
$$

for all $x, y \in X$, where $a_{i} \geq 0$ for each $i \in\{1,2, \cdots, 5\}$ and $\sum_{i=1}^{5} a_{i}<1$. Then $T$ has a fixed point.

Corollary 2.4. (Nadler [3]) Let $(X, d)$ be a complete metric space and let $T$ be a mapping from $(X, d)$ into $(C B(X), H)$ satisfies

$$
H(T x, T y) \leq \alpha d(x, y)
$$

for all $x, y \in X$, where $0 \leq \alpha<1$. Then $T$ has a fixed point.

Corollary 2.5. ([4]; page 5 and [5]; Page 31) Let $(X, d)$ be a complete metric space and let $T$ be a mapping from $(X, d)$ into $(C B(X), H)$ satisfies

$$
H(T x, T y) \leq \beta[D(x, T x)+D(y, T y)]
$$

for all $x, y \in X$, where $\beta \in\left[0, \frac{1}{2}\right)$. Then $T$ has a fixed point.

Corollary 2.6. Let $(X, d)$ be a complete metric space and let $T$ be a mapping from $(X, d)$ into $(C B(X), H)$ satisfies

$$
H(T x, T y) \leq \gamma[D(x, T y)+D(y, T x)]
$$

for all $x, y \in X$, where $\gamma \in\left[0, \frac{1}{2}\right)$. Then $T$ has a fixed point. 
Corollary 2.7. Let $(X, d)$ be a complete metric space and let $T$ be a mapping from $(X, d)$ into $(C B(X), H)$ satisfies

$$
H(T x, T y) \leq \alpha d(x, y)+\beta[D(x, T x)+D(y, T y)]
$$

for all $x, y \in X$, where $\alpha+2 \beta<1$. Then $T$ has a fixed point.

\section{REFERENCES}

[1] S. Banach, Sure operations dans les ensembles abstraits et leur application aux equations integrales, Fund. Math. 3 (1922) 133-181.

[2] G. E. Hardy and T. D. Rogers, A generalization of a fixed point theorem of Reich, Canad. Math. Bull. 16 (1973), 201-206.

[3] N.B. Nadler Jr., Multi-valued contraction mappings, Pacific J. Math. 30 (1969) 475-488.

[4] S. Reich, Kannan's fixed point theorem, Boll. Un. Mat. Ital. 4 (1971), 1-11.

[5] S. Reich, Fixed points of contractive functions, Boll. Un. Mat. Ital. 5 (1972), 26-42.

[6] I.A. Rus, Generalized Contractions and Applications, Cluj Univercity Press, Cluj-Nappa, 2001.

Department of Mathematics, Semnan University, P. O. Box 35195-363, Semnan, IRAN.

E-mail address: madjid.eshaghi@gmail.com, h.baghani@gmail.com

khodaei.hamid.math@gmail.com ,ramezanimaryam873@gmail.com 